\title{
Connecting through the reinforcement - design, testing and construction of a folded reinforced glass structure
}

\author{
Paulo L. Carvalho, ${ }^{a}$, Paulo J. S. Cruz ${ }^{\mathrm{a}}$ and Frederic A. Veer ${ }^{\mathrm{b}}$ \\ ${ }^{a}$ School of Architecture, University of Minho, Guimarães, Portugal \\ ${ }^{\mathrm{b}}$ Faculty of Architecture, Delft University of Technology, Delft, The Netherlands
}

Submitted 3 November 2014

Revised 27 November 2014

Accepted 14 December 2014

\begin{abstract}
A reinforced glass folded structure has been developed using an innovative connection method. The concept relies on extending the reinforcement outwards from the laminated glass and using it to transfer a significant part of the load. The goal is to accomplish a glass element with high stiffness, connected by using a discrete almost invisible and easily assembled/disassembled mechanism. This paper addresses the main issues regarding the design and fabrication of a $90^{\circ}$ folded structure, the experimental investigation of the out-of-plane compressive response and the construction of a full-scale prototype $(2,95 \mathrm{~m}$ high and $5,5 \mathrm{~m}$ long $)$ at the campus of the University of Minho. It is demonstrated that the system offers both structural and aesthetical advantages. It combines a specific aesthetic, deriving from its hybrid character, with a considerable amount of out-of-plane compressive strength before and after failure.
\end{abstract}

Keywords: Reinforced glass, connection detail, folded structure, prototype

\section{Introduction}

The detail of glass connections has received significant contributions in the recent years due to important technological improvements concerning the capacity to efficiently bond glass to metal. It not only has a significant impact on the structural behaviour of the solutions but also opens several new fields of design research (O'Callaghan, 2007; Bagger, 2010; O'Callaghan \& Bostick, 2012; Puller, 2012; Neugebauer, 2013). Among the several solutions available to the designers, embedded connections, in which the metal part is bonded to at least two glass panes with stiff interlayers such as SentryGlas ${ }^{\circledR}$, are of particular interest. Both glass and metal elements tend to lose part of their individual identity fusing into a unified hybrid component. In this case, the relationship between design and fabrication becomes increasingly intricate, mutually influencing each other towards a consistent balance between aesthetics and performance.

\section{Connecting through the reinforcement concept}

Reinforcing glass is an effective method to increase the post breakage behaviour of glass (Feirabend, 2010; Louter, 2011). Once broken, the glass carries the compressive loads while the metal bridges the

\footnotetext{
*Corresponding author: Paulo L. Carvalho, School of Architecture, University of Minho, Campus de Azurém, Guimarães, Portugal. Tel.: +351 253510 500; E-mail: paulo.carvalho@arquitectura.uminho.pt.
} 

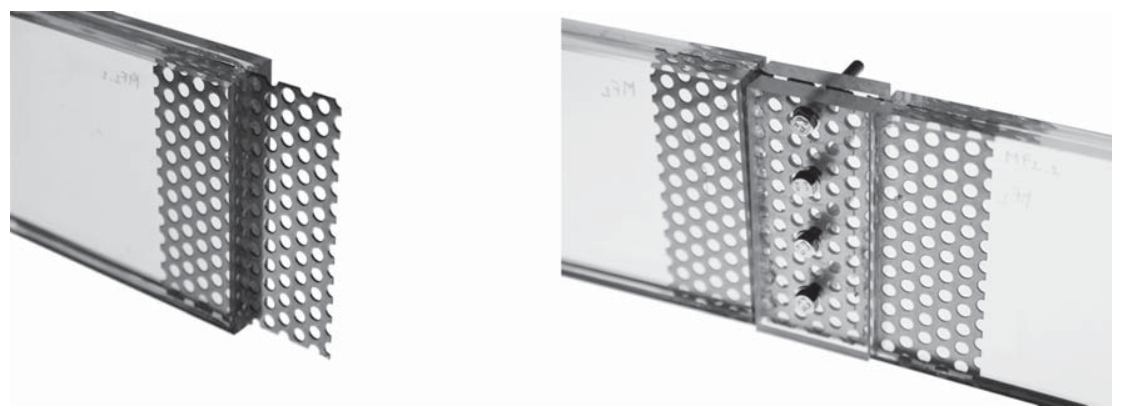

Fig. 1. Concept of extending the reinforcement outwards of the laminate to become the basis for the connection.

tensile loads together with a suitable polymeric interlayer. This interesting structural concept may be enhanced if the reinforcement plays an active role in connecting the glass elements. To achieve this, it is proposed to extend the reinforcement outwards of the laminated glass (Fig. 1).

The purpose of connecting through the reinforcement is the resulting ability to visually dematerialize the connection element. Due to the inevitable opaqueness of metal, instead of seeking to minimize its size, it is proposed to dematerialize it, replacing it by a thin perforated steel plate embedded in the laminate (Carvalho, 2014). Similar to the concept of reinforced glass, the connection relies for its mechanical behaviour on the combination of the significant compressive strength of glass and the significant tensile strength of steel. Besides extending the reinforcement to the outside of the laminate, the glass-to-glass contact must be intermediated by a suitable intermediary layer that can deform under compression.

The effectiveness of the reinforced glass connection system relies on the combination of three load transfer mechanisms (Fig. 2):

- Adhesive, between glass and steel perforated plate by means of at least two adhesive interlayers;

- Mechanical, between the perforated steel plate and polycarbonate, using steel bolts and nuts;

- Contact between glass and polycarbonate edges with the aid of silicone for sealing purposes.

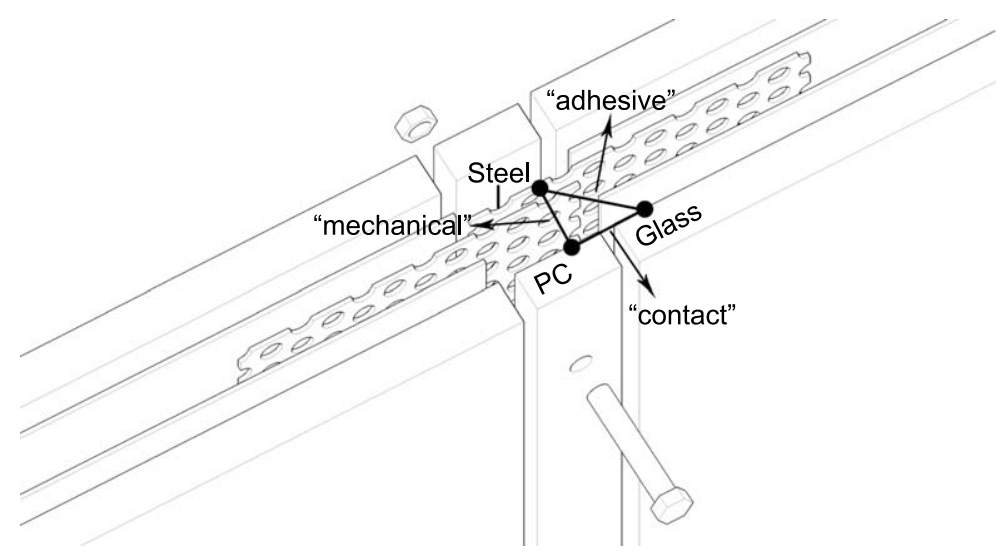

Fig. 2. Scheme of the three main materials that compose the investigated connection and the correspondent three load transfer mechanisms. 
The combination of the three-load transfer mechanisms will allow for an even load transfer. In the end, the distributed stress and the visual dematerialization become conceptually congruent.

\section{Design premises and prerequisites}

The hybrid condition of the connected through the reinforcement element, with the main materials embedded in one compact solution makes the distinction between glass and connection irrelevant. Visually speaking, the "reinforced glass is the connection". With this main premise in mind, a series of fundamental design requirements were identified. The capacity to achieve a smooth optical transition between the glass elements is desired. The joints are also considered critical points in terms of transparency. Therefore, the connection design seeks to reduce the joint width as much as possible, without compromising its own transparency or the mechanical properties. The several materials that compose the connection were integrated as much as possible within the laminate thickness in order to preserve the reflective integrity of the glass surface. It will also be beneficial in terms of maintenance to prevent the accumulation of water or dirt on any prominent profile.

The ductile failure behaviour achieved with this design (Carvalho, Cruz \& Veer, 2012, 2013) must be preserved. The materials making the connection must keep their characteristics that allow for effective and even load transfer. Dimensional tolerances must allow for fabrication tolerance and the inevitable temperature changes. Simplicity of the design solution is essential in order to allow considerable constructional flexibility. This means that the design solution must allow for the development of several glazing configurations with minor adaptations to the base detail.

The capacity to pre-fabricate the glass module as much as possible, leaving for the construction site just the mechanical assembly, is mandatory. Additionally, both the work in execution and the assembly work must be kept as simple as possible. Only then is it possible to meet the required high standards of quality without major changes on the production structure. It will also improve the future acceptance of the solution for real applications. If a glass panel needs to be replaced, the required disassembly must also be as simple as possible. Finally, the detail must provide good water tightness as well as space for an efficient sealing of the interlayer along the protruding steel boundary.

\section{The technological challenge of laminating glass with protruded elements}

The task of integrating a metal piece inside a laminated glass unit requires the application of specific production techniques. Contrary to standard laminated glass, the inclusion of a third piece in between the glass panels creates uneven contact, demanding an efficient removal of the air inside to achieve a good final result. For the current investigation, the only method available for the fabrication of the specimens was the silicone blanket system (Fig. 3). It is a lamination method targeted for industrial use, known to offer very good productivity at low cost. Compared to the alternative vacuum bag system, the main advantage is the simplicity of the preparation work and the avoidance of waste resulting from the process, since the silicone blanket is re-usable.

However, it also revealed during the investigation that the elasticity of the silicone blanket tends to apply a considerable force during the vacuum stage that causes displacement of the glass 

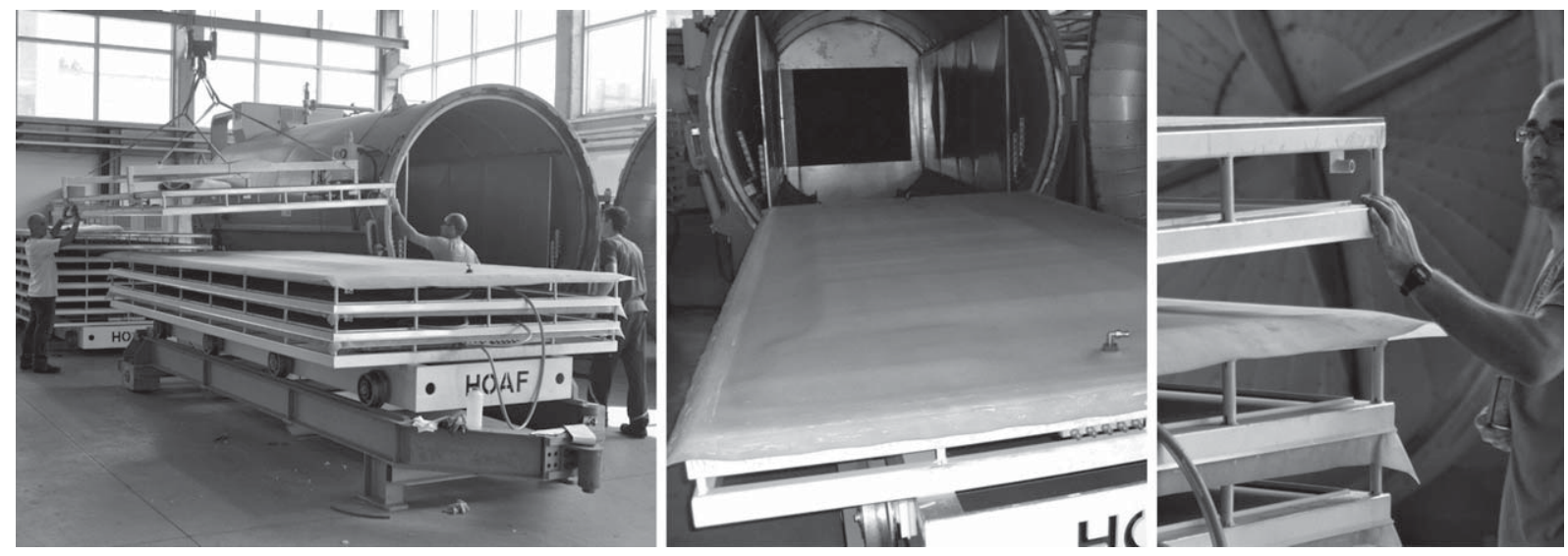

Fig. 3. View of the stacked table structure (left), silicone blanket covering the table (centre) and detailed view of the sealing mechanism performed by the steel angles on the edges of the tables (right).

panes. Although this displacement was just a few millimetres, which for a normal laminated glass application is usually not problematic, for the investigated technique it is fatal. This lamination process is considered more suited for large glass panes where the self-weight acts as a retention mechanism to the imposed stress by the silicone blanket. Additionally, it was clear that this displacement tendency was accentuated by the asymmetrical disposition of the glass panes. When it is vacuum pumped, the silicone blanket tends to concentrate the elements as vertically aligned as possible, preventing staggered placement. During fabrication a simple timber shim was used to fix and protect the metal plate from being deformed. Fixing the metal to the timber profile was found to be insufficient since the glass was free to move aided by the very low friction coefficient of the SG interlayer.

The initial prototypes revealed some dimensional inaccuracies after the lamination process, requiring the investigation of different solutions to prevent it without compromising the premises. The design development of the connection detail, described in detail in the next section, provided until a certain stage considerable inputs to it, however the inherent complexity of most of the initial design versions revealed inhibitive for accomplishing a satisfactory result. The conviction was that the solution should be simplified as much as possible. To do so, it was decided that the lamination problem needed to be solved outside the scope of the connection design.

A method to accurately place and fix the protruded steel plate in the correct position during the lamination process was developed. It consisted of the placement of an auxiliary profile to which the protruded steel was fixed. Changing the thickness of the interlayer from $1,52 \mathrm{~mm}$ to $0,89 \mathrm{~mm}$ matched it with the steel thickness. Only then it was possible to fix the plate and assure its correct position before and after lamination. The auxiliary profile used to fix the protruded steel plate was also responsible for fixing the staggered glass panels in the correct position during lamination. Passing a belt over the auxiliary profile and tensioning it before the application of pressure, preserves the relative position between the two glass panes and the protruded steel (Fig. 4 right). For the rest of the protruded insert length, unprotected by this profile, it was decided to use timber profiles, made by using carpentry techniques (Fig. 4 left). 

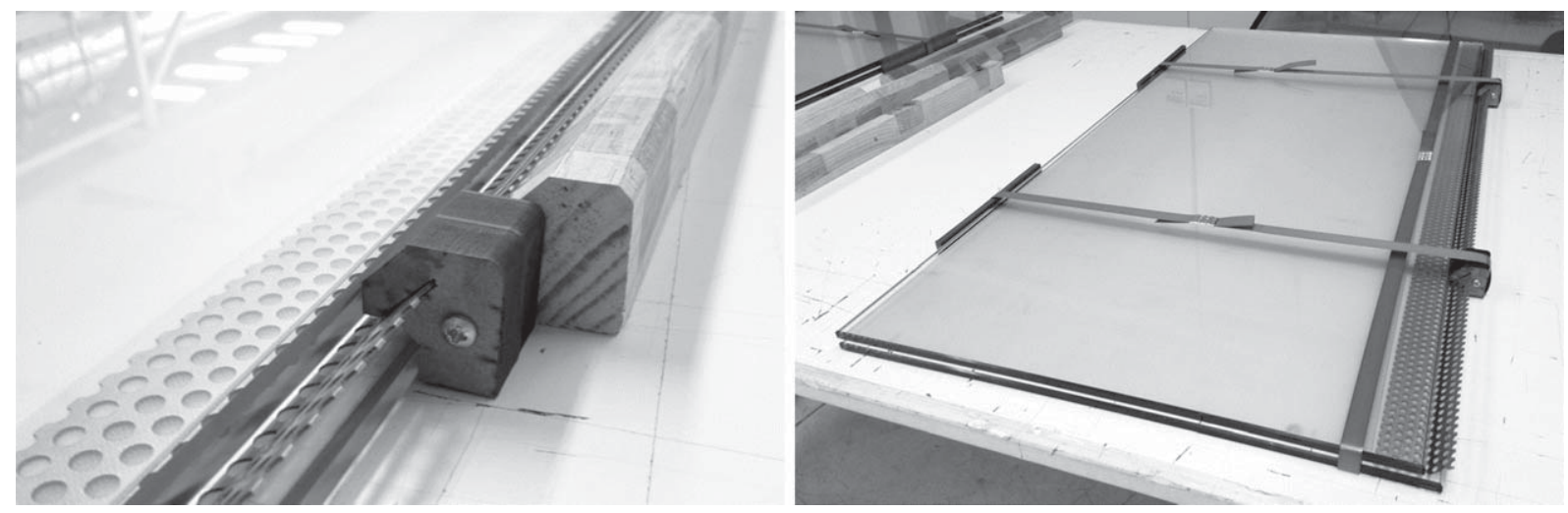

Fig. 4. Auxiliary profiles in position functioning as a gauge before (left) and after (right) tensioning of the belt.

\section{Design of connection detail}

\subsection{Initial version}

The initial version of the connection design used polycarbonate bars to function as a shim mechanism. To allow for symmetry, the glass panels are staggered at a distance of $10 \mathrm{~mm}$. The folded reinforcement layer follows this reconfiguration and is placed with its folding line coincident with the lower edge of the upper glass panel. The geometrical configuration of the pieces is designed in order to execute a shim mechanism both on the upper and lower contact (Fig. 5 left). A timberaluminium prototype of this connection design was made (Fig. 5 right). The adhesive mechanism is simulated, using bolts and nuts to link the aluminium plates to the timber panels. This prototype allowed to empirically test the effectiveness and mechanical capacity of the solution. It was possible to understand that an excessive fragmentation of the intermediate layer (future polycarbonate bar) was prejudicial for the load transmission. As a consequence of the expected, although reduced, deformation of the elements that compose the interface, disintegration of the connection mechanism was easily achieved.
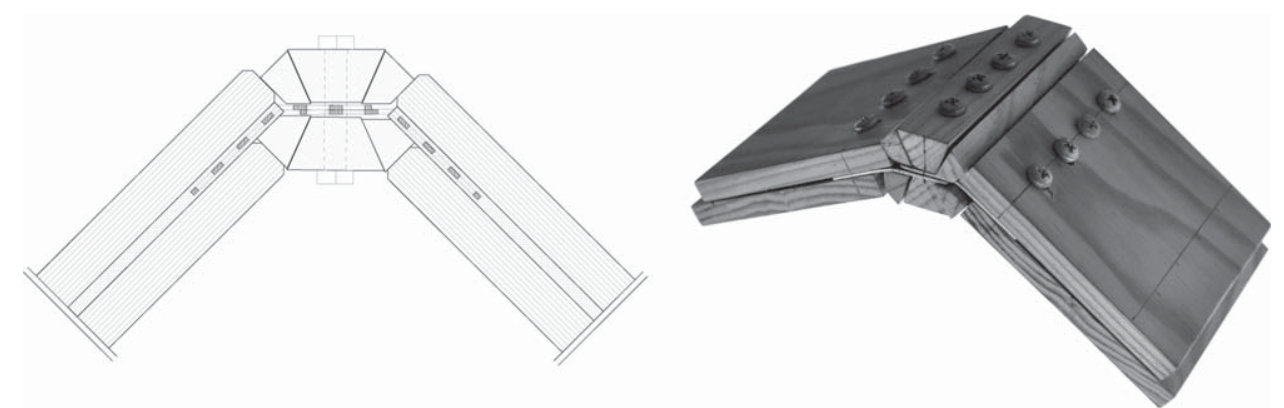

Fig. 5. Detail (left) and timber and aluminium prototype (right) of the initial version of the connection design. 

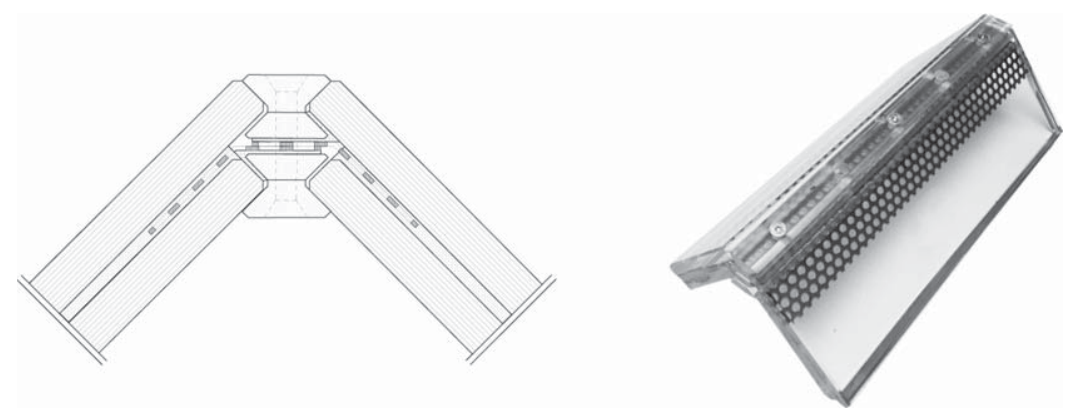

Fig. 6. Detail (left) and prototype (right) of the intermediate version of the connection design.

\subsection{Intermediate version}

The intermediate version of the connection design focused on the three problems arising from the previous designs, namely the tendentiously large width of the joint, the inefficient tensioning mechanisms between glass edges and polycarbonate, and the unintended displacement of elements during lamination process. The polycarbonate bars' geometry was developed to a new configuration based on four vertically aligned bars with symmetrical positioning (symmetry as a design principle to equalize pressure during tightening). The idea was to use the outer bars to create structural contact with the glass edges and effectively perform the load transmission, and the inner bars to aid in the lamination process and assembly tasks. These inner bars would be applied on the individual glass panels before the lamination process by means of a transparent double sided bonding tape. This tape would fix the reinforcement layer to the polycarbonate bar, and also to the glass panel, contradicting the tendency of movement during lamination. The bonding tape was chosen for its ease of application, good adhesion to several materials, capacity to adapt different configurations and for being fully transparent.

The staggering displacement between the glass panels was increased to $13 \mathrm{~mm}$. It enabled to vertically align the glass edges. The position of the reinforcement layer towards the glass panels was adjusted. The folding edge was moved from the upper glass edge to the lower glass edge. It enabled to increase the available thickness to embed the upper polycarbonate bar without overtaking the upper limit of the glass edge. Both the adjustment of the glass-to-glass and reinforcement-to-glass relative position allowed for stabilization of four equal contact surfaces on each side, further refining the symmetry of the system (Fig. 6 left).

Laminating with a fixing element revealed visible improvements in terms of dimensional accuracy. Although not exactly at the same position as before lamination, the staggered position of the glass panes and the relative positioning of the metal layer were acceptable at a first evaluation. When testing the assembly of all pieces, it though revealed to be a difficult task. The steel bolt had to penetrate six layers of material (four polycarbonate hollowed bars and two steel perforated plates). A considerable looseness of the holes diameter was necessary to accomplish the bolt's passage. When tensioning, it became clear that the reduced displacement during lamination had significant impact on the final cohesion of the parts. Once in place, the several layers of polycarbonate bars, although smoothly polished, revealed a visual blurring; it was due to the significant number of overlapping surfaces. A total of 8 transparent surfaces comprised the connection, which when crossed by light result in a significant reflection, visually impairing the results (Fig. 6 right). 

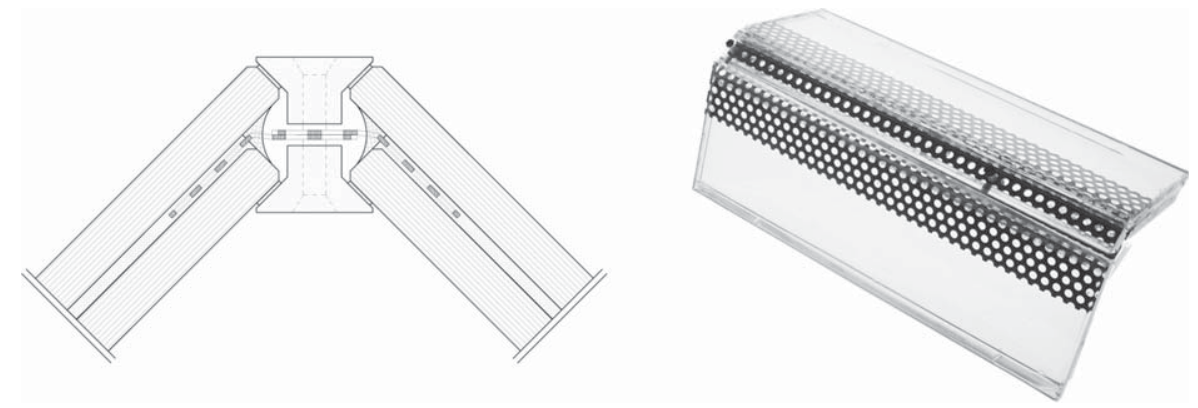

Fig. 7. Detail (left) and prototype (right) of the final version of the connection design.

\subsection{Final version}

The final version comprises two symmetrical polycarbonate bars with a simple configuration. One side of the bar presents a bevelled geometry defining the $90^{\circ}$ fold to be in contact with the glass edge on the upper side, and with the surface of the lower glass pane on the lower side of the connection. This geometry allows for some dimensional tolerance since there is an adaptive deformation capacity of the elements when being tightened. The other side of the polycarbonate bar presents an orthogonal configuration to be inserted in the reduced width joint, close to the reinforcement layers. In the inner gap between the polycarbonate bar and the glass it is proposed to apply silicone for sealing the SG interlayer boundary (penetrated by the protruded reinforcement) as well as on the polycarbonate-toglass contact to provide efficient water tightness to the system (Fig. 7 left). This design solution proved to work efficiently during the assembly and tightening operations. Since the main compressive loads are transmitted on the superior glass edge, this contact showed considerable consistency. Finally, the capacity to see through the polycarbonate bar was thoroughly achieved (Fig. 7 right).

\section{Out-of-plane compressive tests}

An experimental investigation on the mechanical behaviour of a folded reinforced glass component was desired to evaluate its capacity to be efficiently applied in facades and coverings. Without any known reference to test this type of structure, the test setup was designed with the practical application in mind. The out-of-plane compressive behaviour was tested relating to a real application in which wind and other instant distributed loadings are expected. The application of load should be as well distributed as possible, although restricted by the specific folded geometry of the specimen. The capability for handling the specimen during tests, without any mechanical help was considered important for the completion of the tests. For this reason the length of the prototype was limited to $1 \mathrm{~m}$. Although significantly smaller compared with the final prototype to be built, it was considered to be an element large enough to study the behaviour of such type of structure.

\subsection{Specimen description}

The out-of-plane compressive test specimens have a $90^{\circ}$ folded geometry with a total length of $1 \mathrm{~m}$, comprising two symmetrical parts with $0,5 \mathrm{~m}$ of width connected at the centre (Fig. 8). Each 


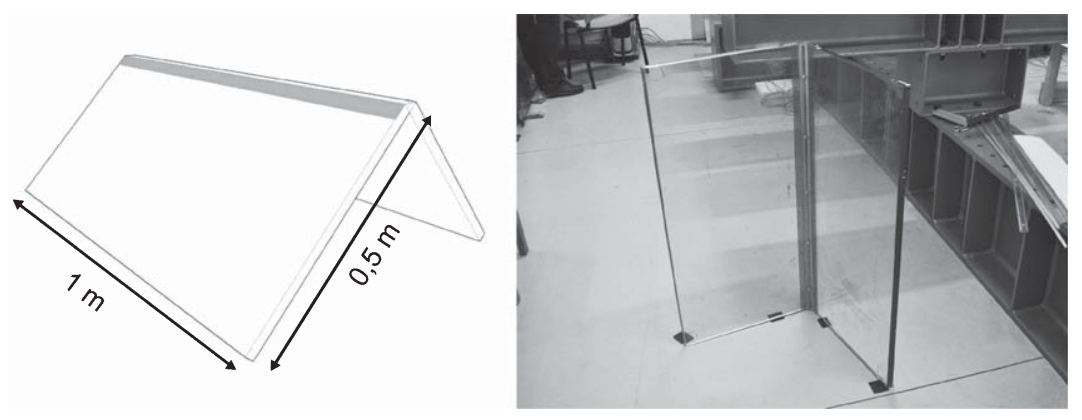

Fig. 8. Diagram of out-of-plane compressive test folded glass specimen (left) and view before test (right).
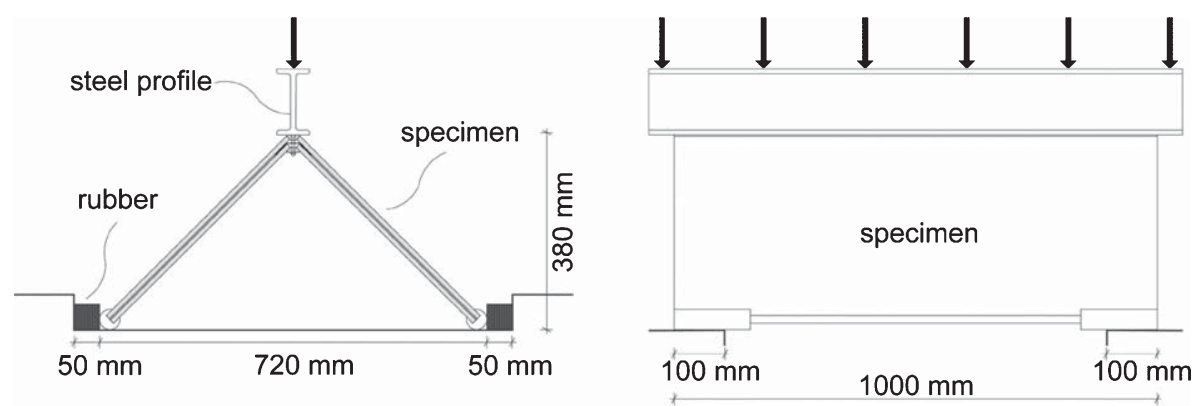

Fig. 9. Folded glass out-of-plane compression test setup, front view (left) and lateral view (right).

part is made of two rectangular shaped pieces of annealed glass of $10 \mathrm{~mm}$ thick, laminated with two sheets of $1,52 \mathrm{~mm}$ thick SG interlayers to which a $1 \mathrm{~mm}$ thick AISI 304 stainless steel perforated plate is semi-embedded. It has the same length as the glass and is $52 \mathrm{~mm}$ wide; $32 \mathrm{~mm}$ of this is embedded in the laminate. The steel plates were previously cleaned with isopropyl alcohol to remove oil and dust and assure good adhesion. Two polycarbonate bars with bevelled edges are placed on the upper and lower part of the connection to realize full contact between the parts once firmly screwed with M5 (8.8 ISO 4017) steel bolts, passing through the aligned perforated steel plate holes, with steel nuts and rings. Five bolts were used in each specimen, at a distance of $200 \mathrm{~mm}$ from each other. One of the specimens exhibited a small flaw close to the centre of the lower edge that had some influence on the results.

\subsection{Test setup}

The folded specimens were placed horizontally and supported on the four corners. A contact length of $100 \mathrm{~mm}$ was ensured in each corner and a cylindrical nylon profile was used as an intermediary between the laminated glass lower edge and the steel base. Due to the expected rotation of the glass panels during the test, the cylindrical shape allows for movement. This profile was previously machined to accommodate the laminate (Fig. 10 centre). The lateral displacement of the specimen was constrained, using steel profiles fixed to the main frame. Some deformation was allowed, using $50 \mathrm{~mm}$ thick rubber blocks in between the nylon and lateral steel break. The specimens were loaded, using a dynamic loading jack of $300 \mathrm{kN}$ with a 'I' steel profile to uniformly distribute the load along 

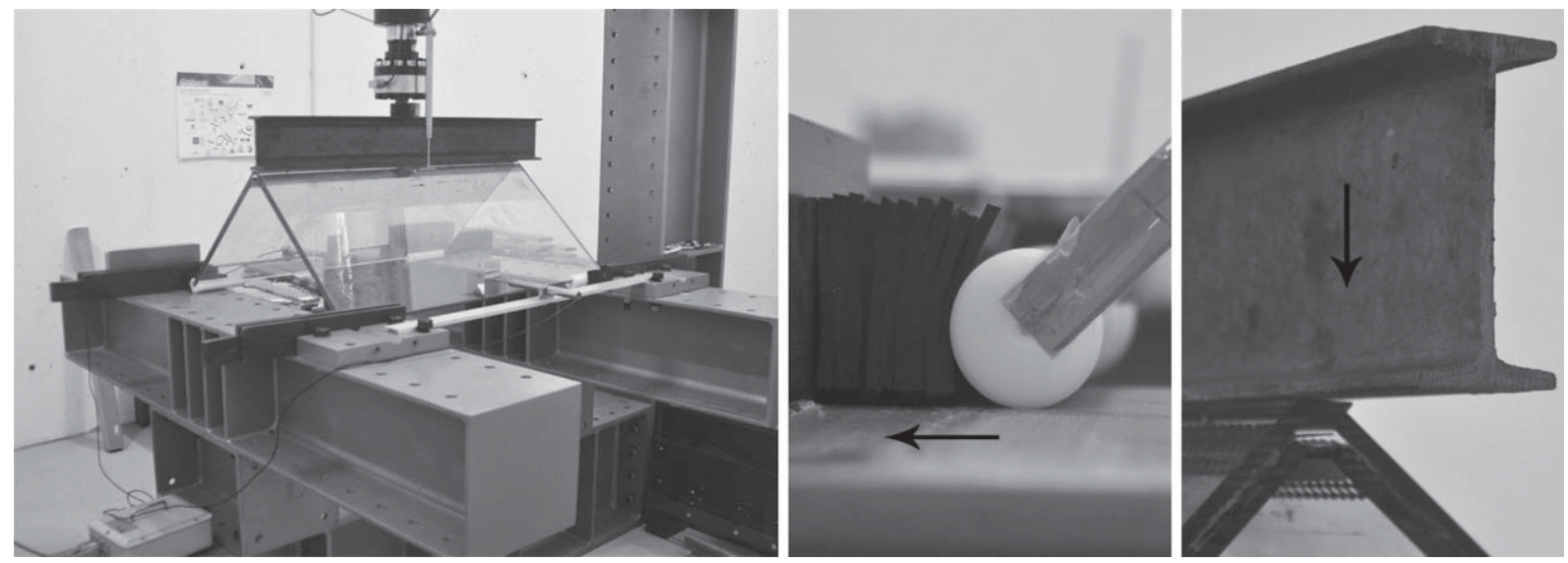

Fig. 10. Folded glass test setup general view (left), detailed view of the lower specimen support (centre) and top contact between steel frame and polycarbonate joint (right).

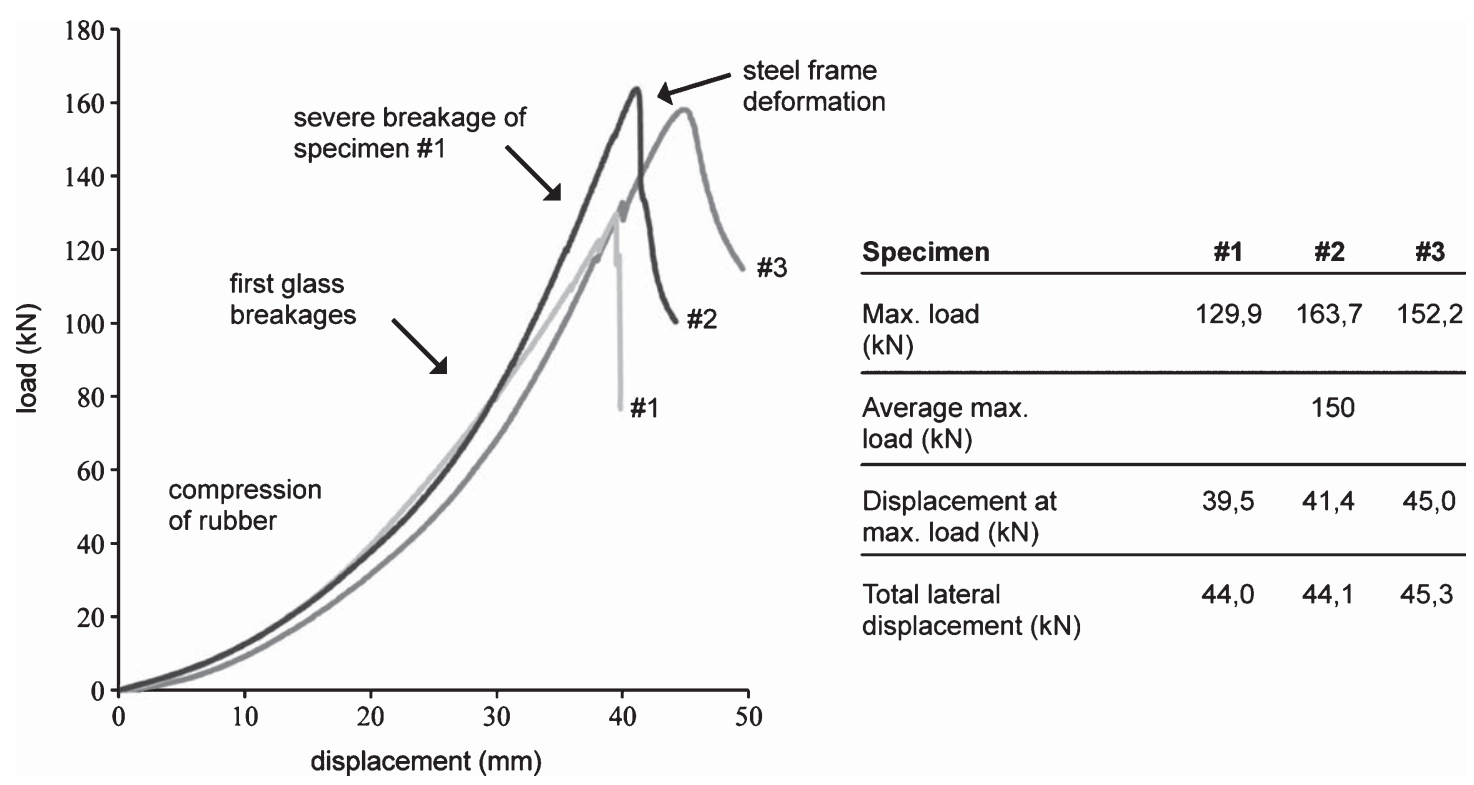

Fig. 11. Load-displacement curves of the out-of-plane compression tests on folded glass specimens (left) and detailed results (right).

the upper edge (Fig. 10 right). The contact is done directly to the polycarbonate bar that composes the joint. The load was applied at a constant displacement rate of $2 \mathrm{~mm} /$ minute and the deformation was measured vertically on the upper joint and horizontally at the lateral edges (horizontal).

\subsection{Test results}

In Fig. 11 the load-displacement curves of the three folded glass specimens tested are shown. It shows the vertical displacement of the folded specimen measured on the top joint of the specimen. 

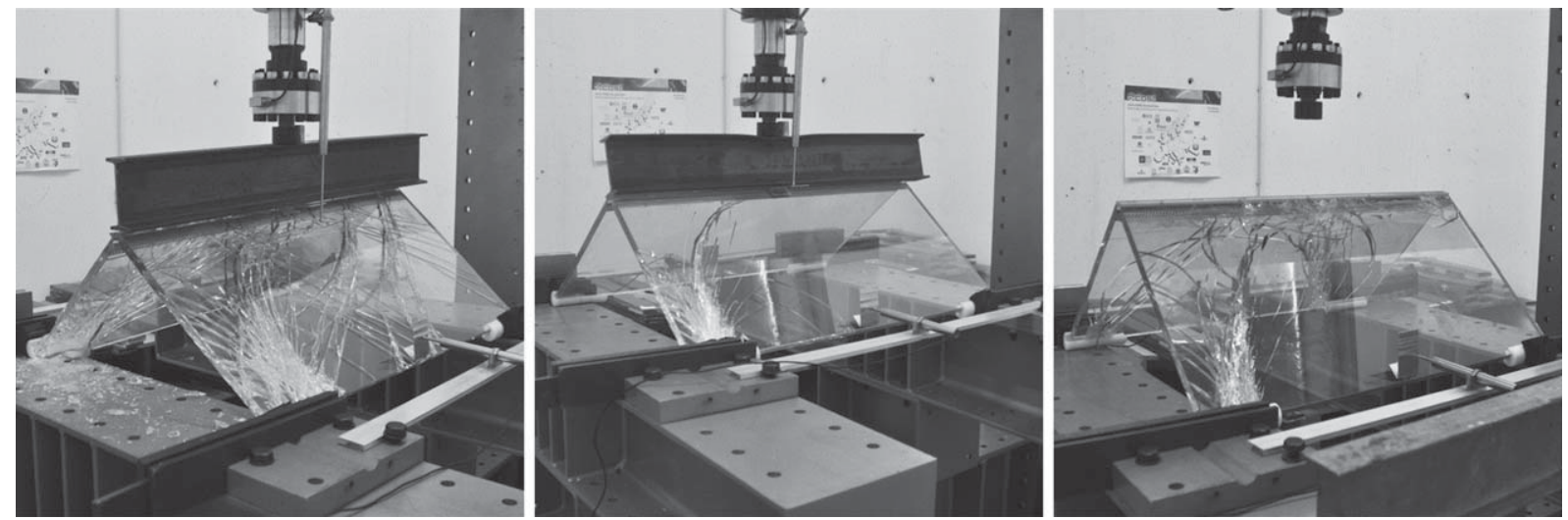

Fig. 12. General view of specimen \#1 (left), \#2 (centre) and \#3 (right) after test.
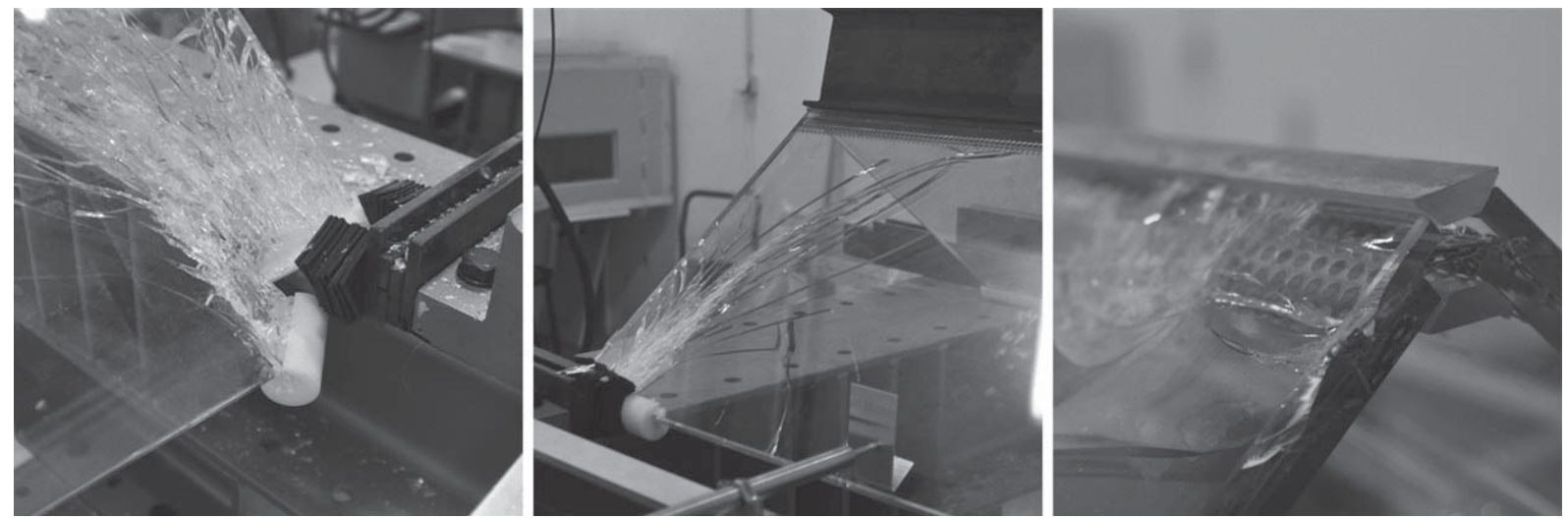

Fig. 13. Close-up view of severe cracking of glass at a lower support of specimen \#1 (left), isolated cracking of glass near a lower support of specimen \#2 (centre) and shell shaped cracking of glass in the upper joint of specimen \#3 (right).

The three curves are very close to each other showing that the tests are quite reproducible. At the beginning of the test, all three specimens began to deform, opening the folded angle and compressing the rubber layers. At around $80 \mathrm{kN}$ of load the first crack appeared on the specimens, starting at one of the lower supports. In the case of specimen \#1 the first cracks appeared in both laminated glass panes at almost the same time, slowly developing along the glass body (Fig. 12 left). Despite the failure of glass, the specimen was capable of taking considerable additional loading. At $109 \mathrm{kN}$ a second series of cracks started close to the lower support on the opposite side (Fig. 13 left). The damage appeared more severe than the previous damage due to the increased load and the asymmetrical deformation already visible on the specimens. These continued to carry the increasing load with increased glass cracking, particularly close to the lower supports. Around $130 \mathrm{kN}$ the fragmentation of the glass close to the initial failure was so severe that it locally disintegrated, which considerably reduced the force.

Specimen \#2 also exhibited its first cracking around $85 \mathrm{kN}$, starting close to a lower support but in only one of the laminated glass panes (Fig. 12 centre). It stayed stable until $126 \mathrm{kN}$ when the other glass pane of the laminate broke showing several simultaneous flaws. Also in this case, despite the cracking 
of both glass panes, the specimen was able to carry a further load increase. It happened around 160 $\mathrm{kN}$, when the glass showed increasing fragmentation, some pieces of which were projected. This occurred in a very localized area, which suffered high stresses (Fig. 13 centre). However, specimen \#2 did not disintegrate. The considerable deformation of the specimen influenced the application of load with the unexpected result that the steel frame started to deform, which prevented any further increase in load. This phenomenon is clearly seen in the load-deformation curve where a soft 'plastic' curve is seen at the top.

Specimen \#3 distinguished itself from the previous two by showing premature cracking of glass starting at the upper edge, close to the point of load introduction (Fig. 12 right). Although the polycarbonate interface prevented direct contact between glass and steel, possibly flaws remaining from the original glass cutting may have triggered it. The cracks developed very slowly, exhibiting a shell-like shape growing in the horizontal direction along the glass body (Fig. 13 right). At around $120 \mathrm{kN}$ of load a simultaneous cracking of four glass panes occurred. This happened close to the two supports on the same side of the specimen, in both laminated panes. It continued to carry an increasing load resulting in new crack branches that developed from both supports. At $130 \mathrm{kN}$ a third main breakage occurred, away from the support area, caused by the pre-test damage mentioned. It meanwhile continued to carry further increases in the load causing considerable deformation of the specimen, until around $150 \mathrm{kN}$, when similarly to the previous test, the steel frame started to deform, which prevented further increased loading.

\section{Full-scale prototype}

A full-scale prototype of folded reinforced glass was built for the International Conference on Structures and Architecture July 2013 held at the University of Minho in Guimarães. The chosen site was located on the east side of the Azurém Campus, flanked by the main entrance hall and the main auditorium. It is a rectangular shaped garden, measuring $20 \mathrm{~m} \times 5 \mathrm{~m}$ covered with grass. Besides the strategic location, this specific site was chosen for the possibility to bury the auxiliary structure and thus achieve a more dramatic display of the system.

The prototype is composed of two folded geometry parallel glass walls. Each wall is composed of seven individual plates, connected by using the developed connection system. All the individual plates measure $2950 \mathrm{~mm} \times 735 \mathrm{~mm}$, with the exception of the first, which measures only $1053 \mathrm{~mm}$ high in order to show the detail clearly. The total assembly comprises 14 panels defining an area of $5,5 \mathrm{~m}$ long and 2,6 $\mathrm{m}$ width (Fig. 14). Each individual plate is composed of: heat-strengthened glass $(2 \times 12 \mathrm{~mm})$, SG foils $(3 \times 0,89 \mathrm{~mm})$, stainless steel perforated plate $(1,2 \mathrm{~mm})$ (In certain panels where the steel perforated plate covers the whole area, only two SG foils were used).

One of the walls is fully 'reinforced', exhibiting glass panels with perforated sheets in its entire surface, while the other exhibits a freer arrangement, alternating zones with and without reinforcement. The purpose is to clearly show the flexibility of the designed connection system in creating structures. The ability to drastically reduce the amount of embedded perforated plate is created by the excellent behaviour of the adhesive mechanism studied during the experimental investigation (Cruz, Veer \& Carvalho, 2011). The fact that the polycarbonate bar of the joint has a reduced width of only $16 \mathrm{~mm}$, and exhibits a polished and recessed surface in relation to the glass plane, contributes to the desired optical fading of the joint. In the traditional systems, the joint is where the emphasis happens, which prevents a subtle definition of the transparent planes that compose it. 


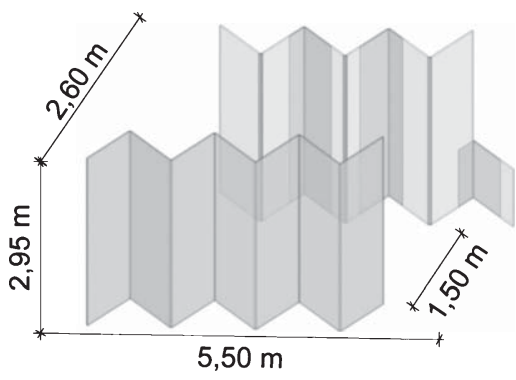

Fig. 14. Graphic representation of the prototype.
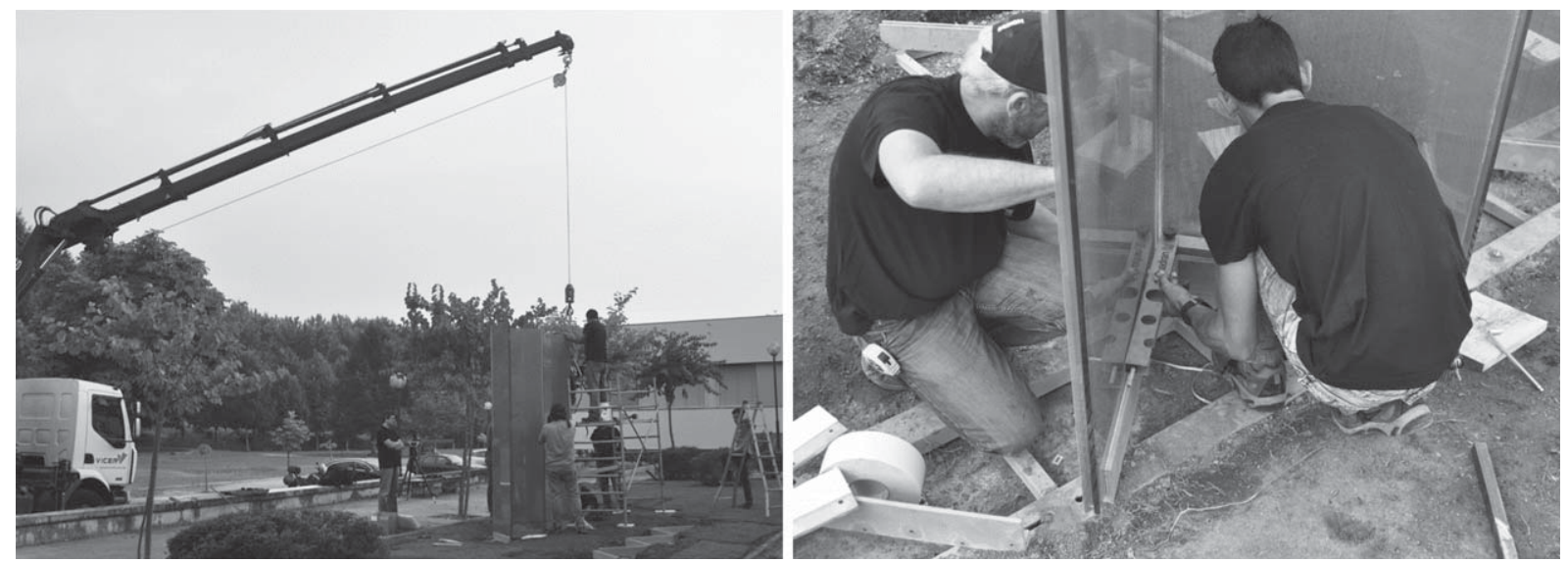

Fig. 15. Placement of the panels in position, using a crane (left) and verification of the angle between panels (right).

The assembly work was done with the help of a 30-m arm crane, in order to lift the panels, move them to the correct position and allow a slow and controlled descent (Fig. 15 left). The first wall to be assembled was the fully reinforced wall. It was decided to start with the middle panels and build outwards; this in order to reduce and dissipate any relative positioning error. However, this precaution was found to be not necessary and the second wall was assembled in a single row, from one edge to the other.

It became clear during the assembly that a 'learning by doing' process was happening. The first panels took several hours to fix in the position, while the last were placed and fixed in less than 20 minutes. The adjustment of the panels in a $90^{\circ}$ position to the clamping profiles was at a certain point difficult, further delaying the process (Fig. 15 right). However, in a real building application the aim will be to avoid this type of assembly and simplify the process.

At the end, the system delivers a specific aesthetic deriving from its essence, in other words, what materializes is also that what reinforces and structurally connects. The different materials that compose it are characterized by a certain degree of transparency that, once superimposed, offer a complex game of different degrees of transparencies (Fig. 16). By changing the angle of observation and lighting conditions, the solution shows its architectural potency. The folded geometry ensures high stiffness, allowing it to be self-supporting both in facades and roofs. 

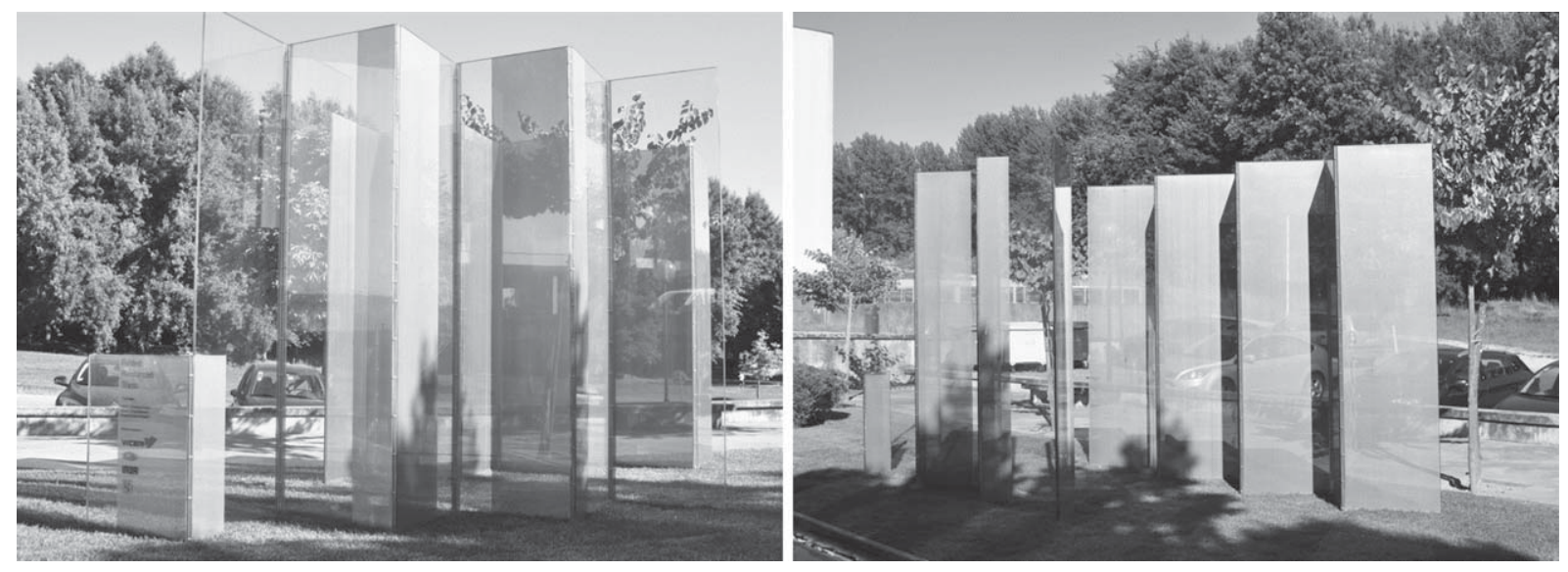

Fig. 16. Different points of view of the finished folded reinforced glass prototype.

\section{Conclusions}

This paper describes the final stage of a research programme focussed on the possibilities of connecting glass panels using embedded reinforcement. The concept was discussed and the materials needed to accomplish it were described with particular emphasis on the design and fabrication issues. The desire to develop a discrete connection solution with folded geometry at $90^{\circ}$ created several technological problems that had to be solved.

The out-of-plane compressive response was experimentally tested and results were quite reproducible. All the specimens showed considerable strength before and after breakage of several glass panes. In fact, the breakage of glass did not affect the increasing of load, which in some cases almost doubled after initial failure. Only one of the specimens showed severe breakage on one of the lower supports compromising the integrity. The others showed considerable overall deformation, which did not threaten the integrity of the glass element but prevented further load increase.

A full-scale prototype was built to evaluate the architectural possibilities of a folded structure, connected by using the investigated connection system. It comprises two parallel walls of $2,95 \mathrm{~m}$ high, disposed to invite people to experience the complex vision of different degrees of transparencies, determined by the level of superimposition, angle of observation and lighting conditions.

\section{Acknowledgments}

This work is funded by FEDER Funds, through the Operational Programme Competitiveness Factors - COMPETE, and Portuguese Funds, through FCT - Foundation for Science and Technology, under the project PTDC/ECM/116609/2010, "S-GLASS: Structural Performance and Design Rules of Glass Beams Externally Reinforced".

\section{References}

Bagger, A. (2010). Plate Shell Structures of Glass. Studies Leading to Guidelines for Structural Glass. PhD Thesis, Technical University of Denmark. 
Carvalho, P. L. L., Cruz, P. J. S., \& Veer, F. A. (2012). Connecting through reinforcement - Experimental analysis of a glass connection using perforated steel plates. Challenging Glass 3 - Conference on Architectural and Structural Applications of Glass. Delft University of Technology, Delft, The Netherlands.

Carvalho, P. L. L., Cruz, P. J. S., \& Veer, F. A. (2013). Reinforced Glass Connection - Concept, test and detail. 2nd International Conference Structures and Architecture ICSA 2013, Guimarães, Portugal.

Carvalho, P. L. L. (2014). (De)materializing Detail. Technology, Structure, Design. Development of a reinforced glass connection technique, University of Minho, Portugal (Doctoral Thesis).

Cruz, P. J. S., Veer, F. A., \& Carvalho, P. L. L. (2011), Perforated steel plate to laminated glass adhesive properties, GPD 2011 - Glass Performance Days International Conference, Tampere, Finland, 219-223.

Feirabend, S. (2010). Steigerung der Resttragfähigkeit von Verbundsicherheitsglas Mittels Bewehrung in Der Zwischenschicht. Universität Stuttgart, Germany.

Louter, C. (2011). Fragile yet Ductile - Structural Aspects of Reinforced Glass Beams. Delft University of Technology, Delft, The Netherlands. Neugebauer, J. (2013). Stainless Steel Fabric as a Connection System for Bomb Blast Glass. In J. Belis, C. Louter \& D. Mocibob (eds.), COST Action TU0905, Mid-Term Conference on Structural Glass (pp. 493-498). London, United Kingdom: Taylor and Francis.

O'Callaghan, J., \& Bostick, C. (2012). The Apple Glass Cube: Version 2.0. In F. Bos, Ch. Louter, R. Nijsse, \& Fred Veer (eds.), Challenging Glass 3 (pp. 57-65). Delft, The Netherlands: IOS Press.

O'Callaghan, J. (2007). An All Glass Cube in NY City. In Glass Performance Days, Proceedings of the 10th International conference (pp. 98-101). Tampere, Finland.

Puller, K. (2012). Untersuchung Des Tragverhaltens von in Die Zwischenschicht von Verbundglas Integrierten Lasteinleitungselementen. Universität Stuttgart, Germany. 